\title{
Global community perception of 'surgical care' as a public health issue: a cross sectional survey
}

\author{
Nurhayati Lubis ${ }^{1 *}$, Meena Nathan Cherian', Chinmayee Venkatraman² and Fiemu E. Nwariaku²
}

\begin{abstract}
Background: In the last decade surgical care has been propelled into the public health domain with the establishment of a World Health Organisation (WHO) designated programme and key publications. The passing of the historic World Health Assembly Resolution (WHA) acknowledged surgical care as a vital component towards achieving Universal Health Coverage (UHC). We conducted the first worldwide survey to explore the perception of surgical care as a public health issue.

Method: The anonymous, cross sectional survey targeted worldwide participants across a range of professional backgrounds, including non-medical using virtual snowball sampling method (in English) using Google Forms (Google Inc., Mountain View, CA, USA) from 20th February 2019 to 25th June 2019. The survey questions were designed to gauge awareness on Sustainable Development Goals (SDGs), UHC, WHO programmes and key publications on surgical care as well as perception of surgical care as a priority topic in public health.

Results: The survey was completed by 1954 respondents from 118 countries. Respondents were least aware of surgical care as a teaching topic in public health courses $(27 \% ; n=526)$ and as a WHO programme $(20 \% ; n=384)$. $82 \%$ of respondents were aware of UHC $(n=1599)$ and of this $72 \%(n=1152)$ agreed that surgical care fits within UHC. While $77 \%$ ( $n=1495)$ of respondents were aware of SDGs, only $19 \%(n=370)$ agreed that surgery was a priority to meet SDGs. 48\% ( $n=941)$ rated surgical care as a cost-effective component of Primary Health Care. 88\% $(n=1712)$ respondents had not read the WHA Resolution on 'Strengthening emergency and essential surgical care and anaesthesia as a component of UHC'.
\end{abstract}

Conclusion: There is still a widespread gap in awareness on the importance of surgical care as a public health issue amongst our respondents. Surgical care was not seen as a priority to reach the SDGs, less visible as a WHO programme and not perceived as an important topic for public health courses.

Keywords: Surgical care, Public health education, Universal health coverage, Sustainable development goals

\footnotetext{
* Correspondence: nlubis@doctors.org.uk

${ }^{1}$ Geneva Foundation for Medical Education and Research, Chemin de Beau-Soleil 12, 1206 Geneva, Switzerland

Full list of author information is available at the end of the article
}

(c) The Author(s). 2021 Open Access This article is licensed under a Creative Commons Attribution 4.0 International License, which permits use, sharing, adaptation, distribution and reproduction in any medium or format, as long as you give appropriate credit to the original author(s) and the source, provide a link to the Creative Commons licence, and indicate if changes were made. The images or other third party material in this article are included in the article's Creative Commons licence, unless indicated otherwise in a credit line to the material. If material is not included in the article's Creative Commons licence and your intended use is not permitted by statutory regulation or exceeds the permitted use, you will need to obtain permission directly from the copyright holder. To view a copy of this licence, visit http://creativecommons.org/licenses/by/4.0/ The Creative Commons Public Domain Dedication waiver (http://creativecommons.org/publicdomain/zero/1.0/) applies to the data made available in this article, unless otherwise stated in a credit line to the data. 


\section{Background}

Within this decade, there has been a massive drive to bring surgical care (including anaesthesia) into the global public health domain. The World Health Organisation (WHO) established the Emergency and Essential Surgical Care (EESC) programme in 2004 with the goal of ensuring the safety and efficacy of clinical procedures in anaesthesia, surgery, orthopaedics, and obstetrics [1]. In 2005, the Global Initiative for Emergency and Essential Surgical Care (GIEESC) was formed as the first coordinated global effort of multidisciplinary stakeholders to meet the need for emergency, anaesthesia, and surgical care in primary healthcare facilities worldwide [2]. The positioning of surgical care and anaesthesia services in the context of universal health coverage (UHC) in the WHO Executive Board agenda for the first time in 2014 led to the passing of the historic World Health Assembly (WHA) Resolution 68.15 on 'Strengthening emergency and essential surgical care and anaesthesia as a component of UHC' in 2015 [3]. Additionally, the publication of a volume dedicated to Essential Surgery in the World Bank Disease Control Priorities 3rd Edition [4] and the launch of the Lancet Commission on Global Surgery Report [5] in the same year, were celebrated as major milestones, particularly within the surgical community.

The 2015 Sustainable Development Goals (SDGs) consisted of 17 goals to be achieved by 2030 and was adopted by 193 countries [6]. This marked a shift in the international community's approach to favouring a horizontal and intersectoral systems approach rather than a vertical disease-specific one [7]. Recognising the necessity of surgical care to achieve both UHC and SDGs, the WHO and Lancet Commission recommended the development of national surgical, obstetric and anaesthesia plans (NSOAPs) [8]. Embedding NSOAPs into existing National Health Sector Strategic Plans will require engaging diverse stakeholders within the Ministry of Health $(\mathrm{MoH})$, and can contribute to the achievement of SDGs 1, 3, 5, 8, 9, 10, 16, and 17 [9].

For these landmark events to translate into action, strong, consistent advocacy and commitment from multi-stakeholders are vital to engaging communities, donors and policy makers [10]. The general public should demand their basic right to timely, safe and affordable surgical care; the economist should see strengthening healthcare system to allow safe surgical services as a cost-effective investment; the health ministries should address this challenge by establishing essential surgical and anaesthesia services as part of broad national programmes; and the policy-makers should be reminded of their commitment to achieve UHC and SDGs to improve quality essential surgical care services.

For effective advocacy there needs to be recognition of the vital role that surgical care plays in meeting the
SDGs and towards achieving UHC. Despite the highprofile advancements mentioned [1-5], we believe that there persists a lack of awareness on this topic as a public health priority amongst healthcare and public health professionals and the general population, apart from a select few. Therefore, we conducted a survey to explore the general awareness and understand the views on essential surgical care as a public health issue, worldwide. To our knowledge, this is the first multi-country survey to seek understanding of the perceived role of surgical care towards achieving UHC. Previous studies have been single-centred and limited to awareness of SDGs amongst university students and staff [11], UHC knowledge amongst nurses [12] and medical student's perception of surgical care in context of global health [13].

\section{Method}

The study protocol was cleared through the Institutional Review Board of the University of Texas Southwestern Medical Centre, which granted the study exempt status. We aimed to sample a diverse, cross-sectional global population. The study aimed to gauge public opinion surrounding SDGs, UHC, WHO programmes, and key documents relating to surgical care. To prevent influencing respondents, we titled the study tool 'Public Health Survey' without mentioning surgical care in the title.

The survey questions were drafted by MNC and the draft revised by the other 3 authors to ensure face validity. The survey consisted of 14 questions (Additional File 1), mostly closed-ended format with checkboxes for ease of analysis. The last question gave respondents the opportunity to provide an open-ended comment. The first four questions were related to demographics; we aimed to include respondents from all six WHO regions [14] and a wide range of professional backgrounds, including non-medical. Respondents were disaggregated into the following categories: doctors, nurses, allied healthcare professionals, public health professionals, non-governmental organisations (NGOs), MoHs, university students, and other. We looked through the entries under 'other' to see if any fit into our operational definitions of the 8 categories and corrected the data.

Questions 6 to 13 were designed to gauge the respondent's knowledge and opinion on SDGs, UHC, WHO programmes, and key documents relating to surgical care. The wording and order of the questions was such that the respondents were not led to any specific answer, and no undefined abbreviations were used.

The survey was anonymous, and participation was voluntary. We did not collect respondent's personal data apart from anonymous demographics. The survey took approximately 3 minutes to answer, employed clear, simple English language, and was piloted on 20 volunteers 
with varying backgrounds in healthcare. Their feedback was taken into account and changes made to ensure the questions were clearly understood. The response from this pilot group was not included in the final analysis.

The survey was conducted over a 4-month period from 20th February 2019 to 25th June 2019. We did not set an aim for the number of respondents, as the study was not powered, and no statistical significance analysis was carried out. The survey was completed online using Google Forms (Google Inc., Mountain View, CA, USA) with a user-friendly interface. The survey link was shared via email networks to a wide range of recipients. The recipients were encouraged to further share the survey widely through their global networks to achieve a virtual snowball sampling method [15]. To increase coverage, the survey link was also circulated via social media platforms including WhatsApp, Twitter, and Facebook.

Google Forms software automatically collated the study data by generating an Excel worksheet which was used for data analysis. We used relative frequency statistics to analyse the closed questions. For the free text comments, the responses were organised into themes and formed the basis of an interpretative discussion.

The questionnaire was designed such that respondents were not able to progress to the next question without

Table 1 Respondents by $\mathrm{WHO}$ regions

\begin{tabular}{|c|c|c|c|c|c|c|c|c|c|c|c|}
\hline \multirow{2}{*}{$\frac{\text { European }}{\text { Belgium }}$} & \multirow[b]{2}{*}{1} & \multirow{2}{*}{$\begin{array}{l}\text { The Americas } \\
\text { Argentina }\end{array}$} & \multirow[b]{2}{*}{2} & \multicolumn{2}{|l|}{ African } & \multicolumn{2}{|c|}{ Eastern Mediterranean } & \multicolumn{2}{|c|}{ South Eastern Asia } & \multicolumn{2}{|c|}{ Western Pacific } \\
\hline & & & & Angola & 1 & Afghanistan & 12 & Bangladesh & 7 & Australia & 27 \\
\hline Bulgaria & 1 & Bahamas & 1 & Burkina Faso & 15 & Bahrain & 2 & Bhutan & 118 & Cambodia & 2 \\
\hline Bosnia & 1 & Belize & 1 & Burundi & 6 & Egypt & 7 & Thailand & 21 & Fiji & 3 \\
\hline Croatia & 8 & Bolivia & 2 & Botswana & 2 & Iran & 14 & India & 271 & China/Taiwan & 4 \\
\hline Czech Republic & 1 & Canada & 36 & Cameroon & 13 & Iraq & 4 & Indonesia & 41 & Japan & 14 \\
\hline Denmark & 3 & Colombia & 3 & Chad & 1 & Kuwait & 3 & Myanmar & 7 & Laos & 3 \\
\hline France & 7 & Chile & 2 & $\mathrm{DRC}$ & 6 & Jordan & 4 & Nepal & 25 & Malaysia & 5 \\
\hline Georgia & 1 & Brazil & 7 & South Sudan & 7 & Lebanon & 1 & Sri Lanka & 1 & Mongolia & 5 \\
\hline Germany & 19 & Guatemala & 1 & Ethiopia & 95 & Morocco & 2 & Total & 491 & New Zealand & 3 \\
\hline Greece & 1 & Haiti & 2 & Gambia & 3 & Pakistan & 31 & & & PNG & 1 \\
\hline Hungary & 1 & Honduras & 11 & Ghana & 28 & Saudi Arabia & 3 & & & South Korea & 3 \\
\hline Italy & 4 & Mexico & 72 & Guinea & 1 & Somalia/Somaliland & 12 & & & Singapore & 3 \\
\hline Luxemburg & 1 & Nicaragua & 4 & Ivory Coast & 2 & Syria & 1 & & & Vietnam & 5 \\
\hline Malta & 1 & Paraguay & 4 & Lesotho & 1 & Tunisia & 1 & & & Philippines & 2 \\
\hline Macedonia & 1 & Peru & 5 & Liberia & 2 & Yemen & 4 & & & Total & 80 \\
\hline Netherlands & 8 & St Kitts & 1 & Malawi & 7 & UAE & 4 & & & & \\
\hline Romania & 1 & Trinidad & 1 & Mozambique & 3 & Sudan & 22 & & & & \\
\hline Norway & 3 & USA & 350 & Mali & 3 & Eritrea & 1 & & & & \\
\hline Portugal & 1 & Uruguay & 1 & Namibia & 4 & Palestine & 6 & & & & \\
\hline Poland & 2 & Total & 506 & Niger & 1 & Total & 134 & & & & \\
\hline Spain & 1 & & & Nigeria & 140 & & & & & & \\
\hline Switzerland & 16 & & & Rwanda & 6 & & & & & & \\
\hline Turkey & 8 & & & Senegal & 1 & & & & & & \\
\hline Uzbekistan & 1 & & & Sierra Leone & 20 & & & & & & \\
\hline Ukraine & 1 & & & South Africa & 6 & & & & & & \\
\hline United Kingdom & 93 & & & Swaziland & 1 & & & & & & \\
\hline \multirow[t]{6}{*}{ Total } & 186 & & & Tanzania & 7 & & & & & & \\
\hline & & & & Uganda & 66 & & & & & & \\
\hline & & & & Zambia & 59 & & & & & & \\
\hline & & & & Zimbabwe & 8 & & & & & & \\
\hline & & & & Kenya & 35 & & & & & & \\
\hline & & & & Total & 550 & & & & & & \\
\hline
\end{tabular}


choosing an answer option using checkboxes. The only parts that were non-mandatory were the two free text sections (country of origin and comments). Seven respondents did not disclose their country of origin, but we did not exclude them as they answered all the mandatory questions.

\section{Results}

The survey was completed by a total of 1954 respondents from 118 countries across all six WHO regions. Table 1 summarises the respondents by WHO regions; African $(28 \% ; n=550)$, the Americas $(26 \% ; n=506)$, South Eastern Asia $(25 \% ; n=491)$, European $(10 \% ; n=186)$, Eastern Mediterranean $(7 \% ; n=134)$ and Western Pacific $(4 \% ; n=$ 80). Seven respondents did not state their country of origin.

The sex distribution of respondents was fairly equal with $51 \%$ male $(n=995)$ and $49 \%(n=959)$ female. The age distribution was more widespread with the greatest proportion of respondents belonging to the 26 to 35 years $(28 \%, n=556)$, followed by $25 \%$ between 36 to 45 years $(n=492)$. Only $8 \%$ were over 66 years $(n=156)$.

The professional affiliation of the respondents is shown in Fig. 1. The largest proportion of respondents were doctors at $37 \%(n=732)$, followed by public health professionals at $24 \%(n=474)$ and nurses at $9 \%(n=$
167). Of the $9 \%$ in the student subgroup, the majority were medical students $(77 \% n=129)$.

When asked what topics should be taught in public health courses (Fig. 2), reproductive, maternal and child health ranked highest at $81 \%(n=1590)$. Human Immunodeficiency Viruses (HIV), tuberculosis (TB), immunisation, and mental health also ranked high (over 70\%). All the other topics (antibiotic resistance, diabetes, injuries and violence, malaria and humanitarian crisis) scored over $60 \%$, with the exception of cancer at $57 \%$ while surgery lags far behind with only $27 \%(n=526)$.

On evaluating respondents' knowledge of WHO programmes, Fig. 3 shows that over $60 \%$ of respondents identified programmes in HIV, maternal and child health, TB, malaria, immunisation and non-communicable diseases (NCDs). Respondents were less familiar with programmes in tropical diseases $(41 \% ; n=796)$ and humanitarian crisis (35\%; $n=682$ ). Even fewer respondents acknowledged surgical care as a WHO programme at $20 \%(n=384)$, which was on par with ageing $(n=388)$.

With respect to international health policy, $82 \%(n=$ 1599) respondents were aware of UHC. Of this, $72 \%$ $(n=1152)$ agreed that surgical care fits within UHC, while $14 \%(n=220)$ said it did not and $14 \%$ did not know. In comparison, $77 \%$ respondents were aware of

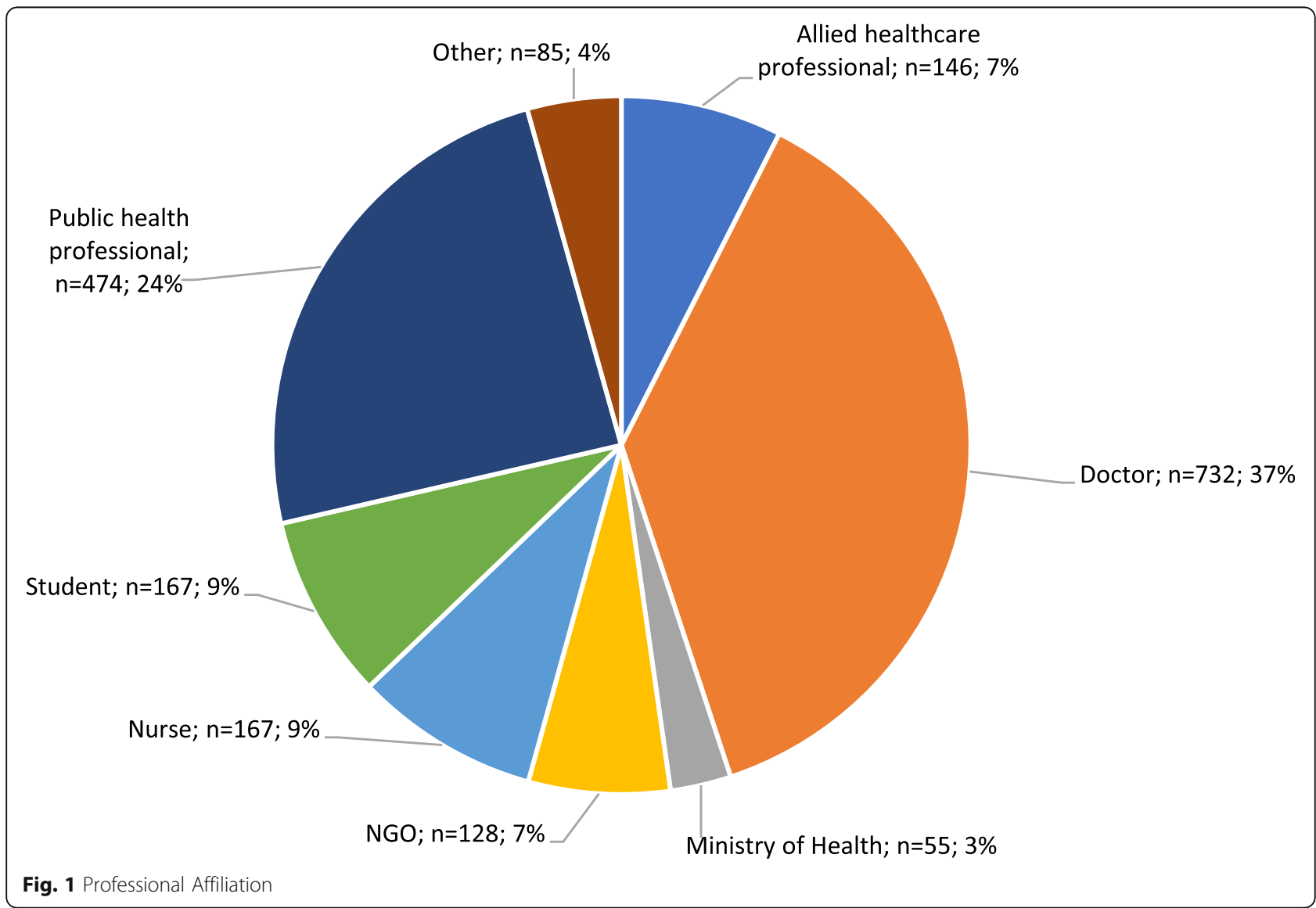



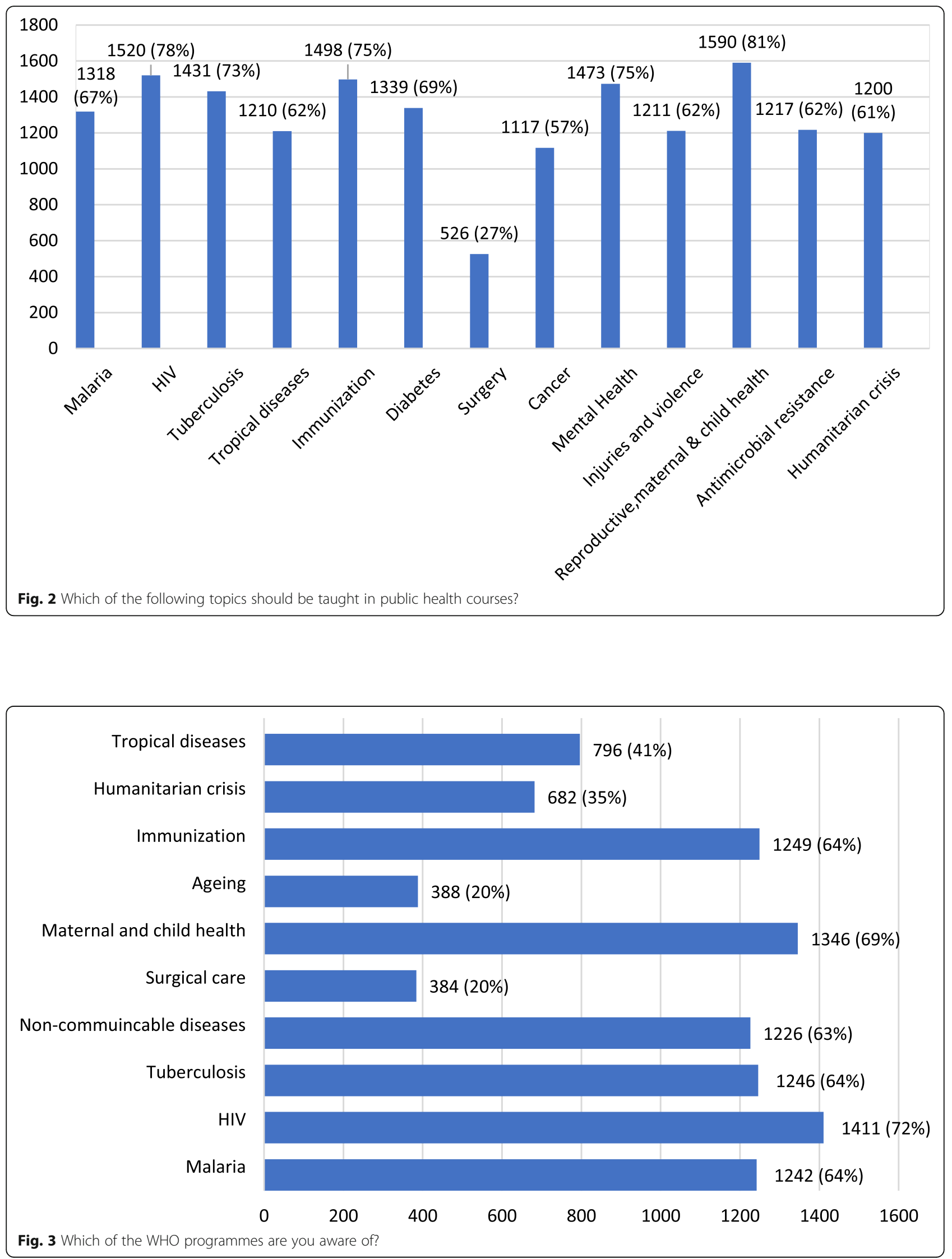
SDGs $(n=1495)$ but only $19 \%(n=370)$ think that surgery is a priority to reach SDGs, which again is by far the lowest compared to $73 \%(n=1436)$ agreeing with reproductive, maternal and child health as a priority (Fig. 4).

Only $25 \%$ of the respondents $(n=494)$ left a comment in the free text box provided at the end of the survey. However, after excluding unrelated comments ('thank you', 'no comments', or email addresses) the number dropped to 394 and relevant comments are further considered.

Less than half respondents $(48 \% ; n=941)$ rated surgical care as a cost-effective component of Primary Health Care while $28 \%(n=549)$ think surgical care is not and the remainder $(24 \% ; n=464)$ did not know. This was also reflected in the comments section where respondents voice their opinion on the unaffordability of providing surgical care at personal level due to out of pocket expenditure and also at the governmental level $(n=13)$. Comments include surgical care is a last resort intervention', 'a very expensive operation that most people can't afford' and 'most public health specialists don't focus on surgical procedures as we rather focus on solving public health issues in a cost-effective way.'

The overwhelming majority of $88 \%(n=1712)$ respondents had not read the WHA Resolution on surgical care and anaesthesia; and $81 \%(n=1577)$ had not read any of the other three publications (Essential Surgery Volume of Disease Control Priorities, 3rd edition; Global Surgery
Report by the Lancet Commission; Publications on 'surgical care' by WHO) as summarised in Fig. 5. In their comments, 28 respondents asked for access to these documents.

\section{Discussion}

It is encouraging to see that the majority of respondents were aware of both UHC and SDGs (82 and $77 \%$ respectively). This is an improvement from previous studies [11-13]. Although those who were aware of UHC in our survey vastly agree that surgical care fits within UHC, only $19 \%$ agree that surgical care is a priority to reach the SDGs. Furthermore, only 20\% were aware of the WHO programme on surgical care and only $27 \%$ of respondents think surgical care has a place in public health education. There is a disconnect between the respondent's awareness of UHC and SDGs and recognition of surgical care as a public health topic towards achieving this. Surgical care is still not as visible as other public health topics and remains an 'outsider'.

Several public health programmes including maternal and child health, NCDs, humanitarian crisis and tropical diseases clearly involves access to essential surgical services [16]. Still, these programmes often seem to be implemented exclusive of strengthening surgical care services and understood better as priority public health issues as reflected in our survey (Fig. 3). Perhaps this is attributed to the fact that surgical care often does not fit

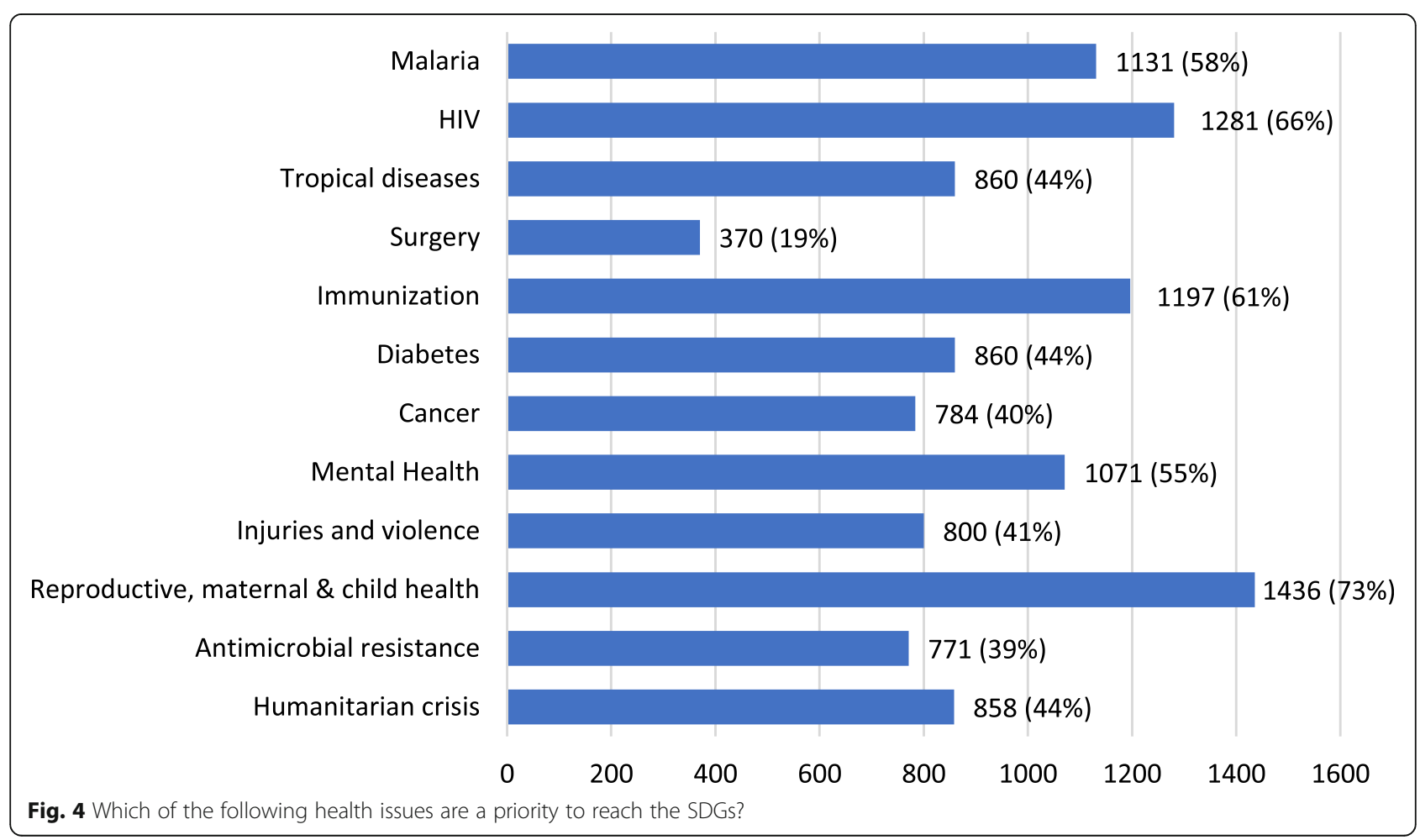




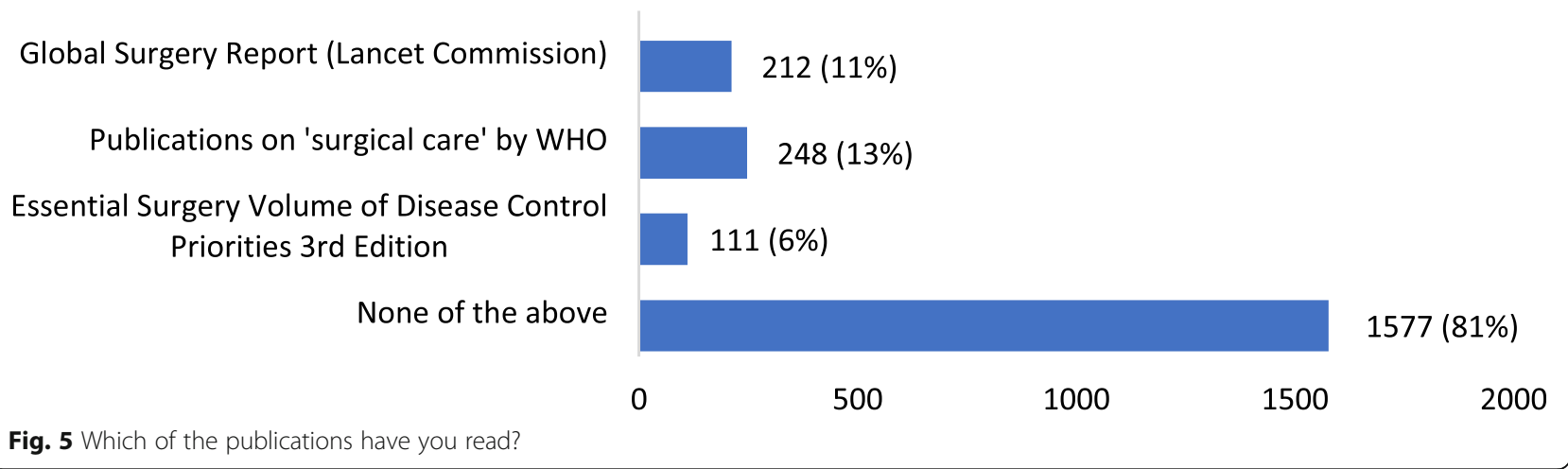

into a vertical programme which is easier to implement with easily measurable endpoints [10]. Surgical care needs to be promoted to all stakeholders as an important cross-cutting essential service for improving quality and safety of patient care from primary to tertiary level healthcare.

Access to surgical services when required, is a crucial component across diseases and throughout our lives. Lack of timely and affordable access to surgery increases the burden of diseases [4], affects economic productivity [17] and psychosocial health [18]. While surgical care is entwined across most public health issues, surgical care alone was not seen as a significant topic by our respondents even though the majority were aware of the UHC and SDGs. Surgery will continue to lag behind in support unless we increase public appreciation on the role of surgical care services in UHC. The Lancet Commission on Global Surgery group recognises the importance of active, prospective engagement strategy by generating a dedicated website and via social media [19]. Through emphasis on education and advocacy, surgical care could be seen on par with other public health initiatives allowing integration in policies and planning at the national level.

It is recognised that surgical care is critical for primary health care and UHC [2, 3]. Promisingly, $48 \%$ of our respondents agree that surgical care is a cost-effective component of Primary Health Care. There is still a false belief amongst the general public that surgical care is expensive, accepting it as a luxury for the fortunate few in low and middle income countries (LMICs) [20, 21]. Policy makers faced with cost-constraints may wrongly overlook surgical provision as something unachievable and less cost-effective than other health interventions. This lack of understanding is yet another barrier. Although the financial cost of surgical expansion is significant, the cost of inaction on national incomes is much greater [5, 22]. Surgical diseases accounted for more than $15 \%$ of the total disability-adjusted life years
(DALYs) lost worldwide, which is more than HIV, TB, and malaria combined [23]. Unfortunately, these strong messages have not been promoted in a simple manner to reach the grassroots, service users and the stakeholders. From our survey it is clear that HIV, TB and malaria remains the favoured topics for public health education in comparison to surgical care (Fig. 2).

The term 'surgical care' itself was seen as being too broad and there was confusion amongst our respondents over what procedures fall under surgical care as stated in their comments $(n=5)$. Several attempts have been made to address this $[24,25]$ and the term surgical conditions is often used in parallel with surgical disease although neither is consistently defined in literature [20]. This reflects the widespread unfamiliarity on this topic. The World Bank Disease Control Priorities 3rd Edition on Essential Surgery identifies 44 surgical procedures as essential on the basis that they address substantial needs, are cost effective, and are feasible to implement [4]. The Bellwether Procedures (caesarean delivery, laparotomy and treatment of open fracture) was introduced as a benchmark for what first level hospitals should be delivering in order to provide emergency and essential surgical care to their population [26]. Having a wellestablished, clear common definition is central to the setting of objectives, priorities, and strategies, communication of goals, and directing of resources [27]. Misperception over the definition could lead to fractions across groups instead of cohesion and cooperation as seen in the global health context [28].

Less than $20 \%$ of respondents have read one or more of the key publications specific to surgical care which are freely available online. We concur that these publications make for a lengthy, concentrated read, thus may not appeal to the public in general. Twenty-eight respondents asked for access to these documents, showing there is lack of awareness not only on the existence of these publications but also the availability to freely download them. The request for more information by our survey respondents was encouraging, and we should 
take advantage of this to promote and achieve surgical care as a public health topic for all including utilising distance learning and incorporating it into public health curriculum. Indeed, 29 of our respondents in their comments welcomed more training, workshops and online courses for surgical care topic in public health. The positive impact of wider access of actionable health information has already been shown [29] and we should use this example to do more to help disseminate the information from the publications [3-5] in a simplified, and freely accessible manner such as via factsheets or toolkits [30], visual imagery [31] or public health education courses. We need to learn from other successful public health advocacy programmes $[32,33]$ in order to increase the visibility of surgical care.

We acknowledge some limitations to our survey. As we were relying on virtual snowball sampling method, we have no control on the survey sample population or size and the response rate is unknown. We could not follow up non-responders. Furthermore, the survey was only in English language and only accessible online. However, the snowball sampling method has been shown to be purposeful method of data collection in qualitative research [34]. We kept the title of our survey generic ('public health survey') to avoid demand characteristics bias or selection bias if potential responders think the topic was not relevant to them or that they were not knowledgeable enough to participate in a survey specifically related to surgical care. Some comments $(n=13)$ did point out that the survey may be biased towards surgical care. Indeed, the intention of our survey was to gauge the general understanding of surgical care as a part of the public health agenda towards achieving UHC through the SDGs.

Despite these limitations, the survey attracted a large number of respondents across a wide range of professions globally with a good spread across high income countries (HICs) and low and middle income countries (LMICs). The sex distribution was almost equal, and the respondents were mainly of working age group. We felt this demographic met our broad target population and resulted in a meaningful outcome. However, we acknowledge that our findings cannot be generalised. Further studies should target a more specific population and utilise a method that can be better controlled against bias within the dataset.

\section{Conclusion}

We have conducted the first worldwide survey to seek understanding of the perceived role of surgical care towards achieving UHC. Although the passing of the historic WHA resolution by the WHO 194 member states was celebrated as key achievement especially by the surgical community, we have shown that a large gap in awareness exists on the importance of surgical care as a public health issue amongst our global respondents. Surgical care is not seen as a priority to reach the SDGs, less visible as a WHO programme and not perceived as an important topic for public health courses.

\section{Abbreviations \\ WHO: World health organisation; EESC: Emergency and essential surgical care; GIEESC: Global initiative for emergency and essential surgical care; UHC: Universal health coverage; WHA: World health assembly; \\ SDGs: Sustainable development goals; NSOAPs: National surgical, obstetrics and anaesthesia plans; MoH: Ministry of health; NGOs: Non-governmental organisations; HIV: Human immunodeficiency viruses; TB: Tuberculosis; NCDs: Non-communicable diseases; DALYs: Disability-adjusted Life years; LMICs: Low and middle income countries; HICs: High income countries}

\section{Supplementary Information}

The online version contains supplementary material available at https://doi. org/10.1186/s12889-021-10936-0.

\section{Additional file 1.}

\section{Acknowledgements}

Not applicable.

\section{Authors' contributions}

MNC developed the study concept and design. NL contributed to data analysis. MNC, NL, CV and FEN contributed to survey dissemination and manuscript writing. All authors read and approved the final manuscript.

\section{Funding}

There is no funding received for this study.

\section{Availability of data and materials}

The datasets used and/or analyzed during the current study are available from the corresponding author on reasonable request.

\section{Declarations}

Ethics approval and consent to participate

The study was granted exempt status and no informed consent was required as approved by the University of Texas Southwestern Medical Center Institutional Review Board.

(ID\#STU-2018-0417)

There was no patient involvement in the study.

The study methods were performed in accordance with relevant guidelines and regulations.

\section{Consent for publication}

Not applicable.

\section{Competing interests}

The author declares that they have no completing interests.

\section{Author details}

${ }^{1}$ Geneva Foundation for Medical Education and Research, Chemin de Beau-Soleil 12, 1206 Geneva, Switzerland. ${ }^{2}$ Office of Global Health, University of Texas Southwestern Medical Centre, Dallas, TX, USA.

Received: 5 November 2020 Accepted: 6 April 2021

Published online: 20 May 2021

\author{
References \\ 1. WHO Emergency and Essential Surgical Care (EESC). 2004. https://www.who. \\ int/surgery/en/. Accessed 21 July 2020.
}


2. WHO Global Initiative for Emergency and Essential Surgical Care (GIEESC). Geneva meeting report. 2015. https://www.who.int/surgery/mission/GIEESC2 005_Report.pdf?ua=1. Accessed 21 July 2020.

3. World Health Assembly (WHA) Resolution 68.15 on Strengthening emergency and essential surgical care and anaesthesia as a component of UHC. 2015. http://apps.who.int/gb/ebwha/pdf_files/WHA68/A68_R15-en.pdf. Accessed 21 July 2020

4. Debas HT, Donkor P, Gawande A, et al. Essential surgery. Disease control priorities, third edition, volume 1. Washington, DC: World Bank; 2015. https://doi.org/10.1596/978-1-4648-0346-8.

5. Meara JG, Leather AJ, Hagander L, et al. Global surgery 2030: evidence and solutions for achieving health, welfare, and economic development. Lancet. 2015;386(9993):569-624. https://doi.org/10.1016/S0140-6736(15)60160-X.

6. United Nations. Sustainable Development Goals - United Nations Development Programme; 2015. https://www.un.org/sustaina bledevelopment/sustainable-development-goals/. Accessed 21 July 2020

7. Béhague DP, Storeng KT. Collapsing the vertical-horizontal divide: an ethnographic study of evidence-based policymaking in maternal health. Am J Public Health. 2008;98(4):644-9. https://doi.org/10.2105/AJPH.2007.123117.

8. Surgical Care Systems Strengthening. Developing national surgical, obstetrics and anaesthesia plans. World Health Organisation 2017. https:// www.who.int/surgery/publications/scss/en/ . Accessed 21 July 2020.

9. Roa L, Jumbam DT, Makasa E, Meara JG. Global surgery and the sustainable development goals. Br J Surg. 2019;106(2):e44-52. https://doi.org/10.1002/ bjs. 11044 .

10. Bath M, Bashford T, Fitzgerald JE. What is 'global surgery'? Defining the multidisciplinaryinterface between surgery, anaesthesia and public health. BMJ Glob Health. 2019;4(5):e001808. https://doi.org/10.1136/bmjgh-2019001808.

11. Omisore A, Babarinde G, Bakare D, et al. Awareness and knowledge of the sustainable development goals in a University Community in Southwestern Nigeria. Ethiop J Health Sci. 2017;27(6):669-76. https://doi.org/10.4314/ejhs. v27i6.12.

12. Tung F, Yan CMV, Tai W, et al. Nurses' knowledge of universal health coverage for inclusive and sustainable elderly care services. Rev Lat Am Enfermagem. 2016;24:e2670.

13. Mehta A, Xu T, Murray M, Casey KM. Medical student perceptions of global surgery at an academic institution: identifying gaps in Global Health education. Acad Med. 2017;92(12):1749-56. https://doi.org/10.1097/ACM. 0000000000001832.

14. WHO member states by region. 2020. http://origin.who.int/about/regions/ en/. Accessed 21 July 2020

15. Baltar F, Brunet I. Social research 2.0: virtual snowball sampling method using Facebook. Internet Res. 2012;22(1):55-74.

16. Strengthening emergency and essential surgical care as a component of universal health coverage. WHO Executive Board $136^{\text {th }}$ session (EB 136/27) 2014. https://apps.who.int/gb/ebwha/pdf_files/EB136/B136_27-en.pdf?ua=1. Accessed 21 July 2020.

17. Warf BC, Alkire BC, Bhai S, Hughes C, Schiff SJ, Vincent JR, et al. Costs and benefits of neurosurgical intervention for infant hydrocephalus in subSaharan Africa. J Neurosurg Pediatr. 2011;8(5):509-21. https://doi.org/10.31 71/2011.8.PEDS11163.

18. Browning $A$, Fentahun $W$, Goh JT. The impact of surgical treatment on the mental health of women with obstetric fistula. BJOG. 2007;114(11):1439-41. https://doi.org/10.1111/j.1471-0528.2007.01419x.

19. Meara JG, Hagander L, Leather AJM. Surgery and global health: a lancet commission. Lancet. 2014;383(9911):12-3. https://doi.org/10.1016/50140-673 6(13)62345-4.

20. Pemberton J, Cameron B. Essential surgical services: an emerging primary health care priority. McMaster Univ Med J. 2010;7(1):5-10.

21. Ozgediz D, Riviello R. The "other" neglected diseases in global public health: surgical conditions in sub-Saharan Africa. PLoS Med. 2008;5(6):e121. https:// doi.org/10.1371/journal.pmed.0050121.

22. Grimes C, Henry J, Maraka J, et al. Cost-effectiveness of surgery in low- and middle-income countries: a systematic review. World J Surg. 2014;38(1):25263. https://doi.org/10.1007/s00268-013-2243-y.

23. WHO Injuries violence and the facts: The scale of the problem. 2014. http:// www.who.int/violence_injury_prevention/key_facts/VIP_key_facts.pdf. Accessed 21 July 2020.
24. Bickler S, Ozgediz D, Gosselin R, Weiser T, Spiegel D, Hsia R, et al. Key concepts for estimating the burden of surgical conditions and the unmet need for surgical care. World J Surg. 2010;34(3):374-80. https://doi.org/10.1 007/s00268-009-0261-6.

25. Debas HT, Gosselin R, McCord C et al. Surgery. In: Jamison D et al eds Disease control priorities in developing countries. 2nd edition. Oxford University Press, New York 2006 67:1245-1246.

26. O'Neill KM, Greenberg SLM, Cherian M, Gillies RD, Daniels KM, Roy N, et al. Bellwether procedures for monitoring and planning essential surgical Care in low- and Middle-Income Countries: caesarean delivery, laparotomy, and treatment of open fractures. World J Surg. 2016:40(11):2611-9. https://doi. org/10.1007/s00268-016-3614-y.

27. Koplan J, Bond T, Merson M, et al. Towards a common definition of global health. Lancet. 2009;373(9679):1993-5. https://doi.org/10.1016/S0140-673 6(09)60332-9.

28. Horton R. Global science and social movements: towards a rational politics of global health. Int Health. 2009;1(1):26-30. https://doi.org/10.1016/j.inhe.2 009.06.003.

29. Royston G, Pakenham-Walsh N, Zielinski C. Universal access to essential health information: accelerating progress towards universal health coverage and other SDG health targets. BMJ Glob Health. 2020;5(5):e002475. https:// doi.org/10.1136/bmjgh-2020-002475.

30. Toolkit for producing patient information. National Health Service United Kingdom 2003. https://www.uea.ac.uk/documents/246046/0/Toolkit+for+ producing+patient+information.pdf. Accessed 22 Aug 2020.

31. Smith KE, Stewart EA. Academic advocacy in public health: disciplinary 'duty' or political 'propaganda'? Soc Sci Med. 2017;189:35-43. https://doi. org/10.1016/j.socscimed.2017.07.014.

32. Success in reaching ' 15 by $15^{\prime}$ ' shows that we can end the AIDS epidemic. UNAIDS Press Release. 2015. https://www.unaids.org/en/resources/ presscentre/pressreleaseandstatementarchive/2015/july/20150719_15x15_ PR. Accessed 21 July 2020.

33. Maher D, Dye C, Floyd K, Pantoja A, Lonnroth K, Reid A, et al. Planning to improve global health: the next decade of tuberculosis control. Bull World Health Organ. 2007;85(5):341-7. https://doi.org/10.2471/BLT.06.037820.

34. Naderifar M, Goli H, Fereshteh G. Snowball sampling: a purposeful method of sampling in qualitative research. Strides Dev Med Educ. 2017;14(3): e67670.

\section{Publisher's Note}

Springer Nature remains neutral with regard to jurisdictional claims in published maps and institutional affiliations.
Ready to submit your research? Choose BMC and benefit from:

- fast, convenient online submission

- thorough peer review by experienced researchers in your field

- rapid publication on acceptance

- support for research data, including large and complex data types

- gold Open Access which fosters wider collaboration and increased citations

- maximum visibility for your research: over $100 \mathrm{M}$ website views per year

At BMC, research is always in progress.

Learn more biomedcentral.com/submissions 